\title{
Liderança Feminina Frente ao Mercado de Trabalho no Município de Vassouras no Período de 1970 a 2010
}

\author{
Claudenir Pereira do Val \\ Universidade Severino Sombra, Centro de Letras, Ciências Sociais \\ Aplicadas e Humanas, Curso de Administração, claudenireuss.br
}

\section{Introdução}

O presente estudo insere-se na linha de pesquisa de "História Política: relações de poder, pensamento político e movimentos sociais", do Programa de Mestrado em História da Universidade Severino Sombra.

O nosso objetivo com esse projeto de pesquisa é analisar o crescimento profissional da mulher, na conquista de seu espaço dentro do mercado de trabalho em cargos de liderança no município de Vassouras, nas diversas áreas e organizações, principalmente, na Universidade Severino Sombra - USS, Instituição de Ensino Superior daquela cidade. O período a ser estudado abrange os anos de 1970 a 2010, recorte temporal significante por coincidir com a implantação da USS, e nos permite traçar um comparativo do cenário anterior com o atual e como se deram a evolução e o crescimento profissional supracitado.

Vassouras é uma cidade da região do Vale do Café, localizada no interior do Rio de Janeiro, com população de aproximadamente 32.495 habitantes, e economia baseada na agricultura, no comércio e no turismo. A Universidade Severino Sombra, fundada em 1967, com o nome de Fundação Universitária Sul Fluminense, tem em seu quadro de pessoal cerca de 1.500 funcionários e figura como a maior empregadora do município e a segunda da região sul fluminense, além de ter considerável representatividade nos aspectos econômicos, sociais culturais.

Com seus costumes, tradições, população simples, hospitaleira e de vida pacata, Vassouras constitui motivo ideal se propusermos discutir a questão de como ser gestora em cidade grande e de interior, e se existe diferença ou algum tipo de preconceito por parte da população, a partir de seus costumes. Quais são as facilidades e dificuldades de a mulher, ao exercer a função de gestora, na cidade em que vive, para se fazer respeitar pelas outras pessoas, e, principalmente, pelo universo masculino? Quais são as características da líder gestora e se a mulher não deve abandonar suas características 
Liderança Feminina Frente ao Mercado de Trabalho no Município de Vassouras no Período de 1970 a 2010

Claudenir Pereira do Val

Primeiros Escritos

(Publicação de Textos, Ensaios e Artigos de Discentes)

femininas, e se, por outro lado, necessita absorver características tipicamente masculinas.

Nas décadas de 1960 e 1970, o feminismo eclode na Europa e nos Estados Unidos, movimento impulsionado pela efervescência política e cultural por que essa regiões passavam na época em que se colocavam em xeque os valores conservadores da organização da sociedade. E' neste contexto que se discute o livro O Segundo Sexo de Simone de Beauvoir ${ }^{1}$ e que as americanas se despem dos sutiãs em praça pública.

As origens do feminismo no Brasil se encontram no século XIX. Essas primeiras manifestações desafiaram ao mesmo tempo a ordem conservadora que excluía a mulher do mundo público (do voto, do direito como cidadã) e, também, propostas mais radicais, que iam além da igualdade política, mas que abrangiam a emancipação feminina, pautando-se na relação de dominação masculina sobre a feminina em todos os aspectos da vida da mulher.

Durante o império, alguns juristas tentaram legalizar o voto feminino, com ou sem o consentimento do marido. A constituição de 1891, não excluía a mulher do voto, pois na cabeça dos constituintes não existia a idéia da mulher como um indivíduo dotado de direitos. Isso fez com que muitas mulheres requeressem, sem sucesso, o alistamento. A constituição republicana de 1889 continha inicialmente uma medida que dava direito de voto para as mulheres, mas, na última versão, essa medida foi abolida, pois predominou a ideia de que a política era uma atividade desonrosa para a mulher. Com o golpe de 1937, ocorreu um longo período de refluxo do movimento feminista, refluxo que se estende até as primeiras manifestações, nos anos 1970. No entanto, isso não significa que durante esse longo período as mulheres não tiveram nenhum papel no mundo público; muito pelo contrário, houve momentos importantes de participação da mulher, como o movimento no início da década de 1950, contra a alta do custo de vida, por exemplo. Céli Pinto, aborda esses grupos de mulheres de forma circunstancial em decorrência de seu objetivo principal que, segundo ela, é o de destacar os grupos feministas, isto é, os que problematizaram e lutaram pela transformação da condição de dominação à qual as mulheres estavam submetidas.

Em 1972, ocorrem eventos que apontam para a história e as contradições do feminismo. Surge uma nova retomada do movimento feminista pelas mãos da advogada Romy Medeiros da Fonseca, o chamado Conselho Nacional de Mulheres do Brasil. Esse movimento torna as questões mais abrangentes, como: "principio da igualdade entre marido e mulher no casamento e "introdução do divórcio na Legislação brasileira". A presença de Romy Medeiros indica uma espécie de transição entre o velho e o novo feminismo, entre o que já se chamava de feminismo "bem-comportado", à moda Bertha Lutz, e um novo feminismo "malcomportado" que começou a enfrentar questões consideradas tabus. Entre os eventos que marcaram a entrada definitiva das mulheres e das questões por elas levantadas, na esfera pública, destaca-se ainda o Ano Internacional da Mulher, em 1975, decretado pela Organização das Nações Unidas (ONU). O feminismo no Brasil se fortalece com o evento organizado para comemorar o Ano 
Liderança Feminina Frente ao Mercado de Trabalho no Município de Vassouras no Período de 1970 a 2010

Claudenir Pereira do Val

Primeiros Escritos

(Publicação de Textos, Ensaios e Artigos de Discentes)

Internacional, realizado no Rio de Janeiro sob o título "O papel e o comportamento da mulher na realidade brasileira", e com a criação do Centro de Desenvolvimento da Mulher Brasileira.

A crescente participação da mulher no mercado de trabalho, a tornou tema de estudo há algumas décadas. Numa dimensão mais contemporânea, surge então a mulher gestora, aquela que tem que liderar, comandar. Se antes tínhamos uma figura tímida, com a intenção de conquistar seu espaço, agora temos a mesma figura aguerrida, que compete com a força masculina, com a obrigatoriedade, muitas vezes, de provar que são tão capazes quanto seus "oponentes".

Diante da transição da força braçal para a era do conhecimento, como elemento que alavanca a organização, aumentaram as possibilidades de atuação da mulher que tem seus talentos associados à colaboração, ao espírito de equipe, à sensibilidade para a necessidade do outro, que sobrevive melhor em tempos de aperto e apresenta maior abertura e flexibilidade para o aprendizado constante. Não podemos deixar de citar, que, muitas vezes, essas características do universo feminino, eram vistas como fraquezas, mas que, a cada dia, tornam-se vantagens no mundo corporativo da atualidade.

Importa lembrar que liderança é tema importante e de extrema complexidade na vida do ser humano. Liderar não é uma tarefa simples, pelo contrário, exige paciência, disciplina, humildade, respeito e compromisso, pois a organização é um ser vivo, e necessita de colaboradores dos mais diferentes tipos. Liderar, de uma forma bem clara, resulta em gestão eficaz e eficiente das pessoas de uma equipe, para que se atinjam os objetivos propostos pela organização. Um gerente eficaz pode ser um bom planejador, um gestor justo e organizado e ainda assim, não ter as capacidades motivadoras de um líder. Pode igualmente, ocorrer o contrário: um gerente ser ineficaz, porém, em contrapartida, ter as habilidades necessárias a uma boa pessoa. Gerência é o que fazemos. Liderança é quem somos.

Uma das consequências da ascensão da carreira profissional da mulher é muitas vezes, ter uma renda maior que a do esposo. Dentro desse contexto procuraremos verificar o comportamento do cônjuge perante esse fato e como a mulher o administra.

Numa situação antagônica ao parágrafo anterior, o fato de a mulher gestora ser independente, "dona do seu nariz", pode torná-la mais exigente e seletiva, e resulta, muitas vezes, em estar solteira, sem constituir família, por não conseguir um companheiro que atenda às suas expectativas e que acompanhe seu crescimento profissional.

Desse modo, esse estudo propõe discutir tal situação, na tentativa de encontrar respostas para possíveis prejuízos à vida afetiva.

Os objetivos apresentados neste trabalho consistirão em atender à problemática apresentada, o que nos leva a propor a seguinte análise: primeiro, os fatores que influenciaram o crescimento profissional da mulher, como a busca pela qualificação 
Liderança Feminina Frente ao Mercado de Trabalho no Município de Vassouras no Período de 1970 a 2010

Claudenir Pereira do Val

Primeiros Escritos

(Publicação de Textos, Ensaios e Artigos de Discentes)

profissional e a importância da implantação da USS com seus diversos cursos no município, como elemento motivador e facilitador; segundo, estudar os diversos papéis que a mulher exerce, ou seja, gestora, mãe, esposa, dona-de-casa etc., e como se dá o equilíbrio da vida profissional com a vida familiar. Por último, analisaremos a função de gestão que ficou, durante muito tempo, em mãos masculinas e como a mulher administra a situação de que não é mais comandada e sim comandante, identificando os desafios, dificuldades e outras situações que envolvem a liderança feminina e como a figura masculina se comporta diante dessa nova realidade.

\section{Referencial Teórico}

Como referencial teórico, a pesquisa se dará a partir de estudos realizados com autores de diversas áreas como as da Administração, Psicologia e Sociologia, autores que sempre tiveram bastante relevância e importância na construção do conhecimento acadêmico e que tratam dos conceitos de liderança, poder, autoridade e gênero.

Através desse estudo, perceberemos como cada autor contribuiu com novos conceitos e idéias que, ao longo do tempo, foram-se sedimentando e alicerçando as teorias sobre o tema. Segundo Chiavenato (s.d.), "o século XX foi o século da Administração. Foi nele que surgiram as principais abordagens administrativas e a Administração se desenvolveu de forma impressionante".

O tema liderança tem sido objeto de estudo do homem ao longo de sua existência. Para falarmos de liderança, é necessário, antes, discorrermos sobre poder e autoridade.

O conceito de poder muitas vezes é confundido com autoridade, mas veremos o quanto é diferente. A partir da Teoria das Relações Humanas, com seu precursor, o sociólogo Elton Mayo, a liderança, o poder e autoridade passaram a ter diferentes abordagens. Ter poder não é o mesmo que ter autoridade. $O$ poder é a "faculdade de forçar ou coagir alguém a fazer sua vontade, por causa de sua posição ou força, mesmo que a pessoa preferisse não o fazer". A autoridade é "a habilidade de levar as pessoas a fazerem de boa vontade o que se quer, por causa de uma influência pessoal"; é ter a capacidade de influenciar os acontecimentos, o pensamento e o comportamento das pessoas. Morgan (1986) destaca que o poder é o meio pelo qual conflitos e interesses são resolvidos; decorre disto que o poder influencia quem consegue o quê, quando e como. De modo geral, o exercício do poder está vinculado a capacidades, enquanto a liderança está atrelada a habilidades. A liderança, muito mais próxima da autoridade, representa o uso justo do poder, a energia que lança e sustenta uma ação ou que transforma intenção em realidade (BENNIS, 2001). É um fenômeno que não se relaciona com posições hierárquicas ou com funções exercidas, mas com a habilidade de influenciar positivamente, convencer, chamar para o comprometimento, motivar e reconhecer o valor do capital humano. A função do líder é facilitar o alcance dos objetivos, mediante a cooperação entre os liderados e, ao mesmo tempo, proporcionar oportunidades para o 
Liderança Feminina Frente ao Mercado de Trabalho no Município de Vassouras no Período de 1970 a 2010

Claudenir Pereira do Val

Primeiros Escritos

(Publicação de Textos, Ensaios e Artigos de Discentes)

seu crescimento e aperfeiçoamento pessoal. O enfoque principal, ao contrário da Escola da Administração Científica, localizava-se nas necessidades individuais e não naquelas da organização.

Os líderes, segundo a Teoria X de Douglas MacGregor (citado por Stoner \& Freeman: 1995), admitem que os liderados não são suficientemente maduros ou motivados, portanto o líder não pode conceder-lhes muita autonomia. A Teoria Y do mesmo autor, em contraste, admite que os liderados são maduros e podem receber autonomia para realizar suas tarefas.

A figura do gestor, proposto pela Teoria Estruturalista, deve ter personalidade flexível, alta resistência à frustração, capacidade de adiar as recompensas e um permanente desejo de realização. Já o líder na Teoria Contingencial deve identificar que atitude, procedimento ou técnica administrativa poderá, numa situação específica, sob circunstâncias específicas e em um momento específico, contribuir melhor para a obtenção dos objetivos da organização (ibidem).

Para John Kotter (1997), a atividade principal de um líder é produzir a mudança. A sua ação deve se pautar sobre três dimensões fundamentais: estabelecer a direção estratégica da empresa, comunicar essas metas aos recursos humanos e motivá-los para que sejam cumpridas. Ele considera que "as capacidades de liderança são inatas, embora todas as pessoas devam ser encorajadas a ser líderes". Todos os líderes de sucesso têm uma grande paixão por algo, paixão essa que é mais forte do que eles e do que a organização; reforça Kotter.

Alguns autores foram pródigos em produções acerca desses temas; contudo, seus estudos generalizaram o exercício do poder no universo organizacional, pouco considerando a atuação feminina na situação de liderança. Talvez, tal fato ocorra porque as mulheres constituiam (e ainda constituem) uma pequena parcela da população que efetivamente conquista posições mais elevadas na hierarquia das empresas.

Existe uma dimensão muito importante, não só para as organizações, mas também para a sociedade como um todo, que é a inserção e participação da mulher no contexto do trabalho e os reflexos da sua maneira de pensar, agir e sentir sobre os fenômenos evidenciados na complexidade organizacional (MADRUGA et. al., 2001).

Ao longo do tempo, ocorreram algumas mudanças que acabaram por influenciar o ambiente organizacional. Dentre elas, contam-se a globalização, as inovações tecnológicas, as mudanças nas exigências dos clientes e os novos e sofisticados modelos de gestão. Sobre esse assunto Madruga et. al (2001) apontam que essas profundas mudanças fizeram com que as organizações revisassem sua postura quanto à visão e a ação estratégica. Pode-se dizer que atualmente as organizações já abrem espaço para a presença feminina em postos de liderança.

Segundo Cappelle apud Menda (2004, p.56), no momento em que as mulheres começaram a se inserir no mercado de trabalho, as questões que envolvem as relações 
Liderança Feminina Frente ao Mercado de Trabalho no Município de Vassouras no Período de 1970 a 2010

Claudenir Pereira do Val

Primeiros Escritos

(Publicação de Textos, Ensaios e Artigos de Discentes)

de trabalho entre a mão-de-obra masculina e feminina começaram a emergir. A maioria dos discursos nas organizações sempre pregou igualdade de condições e oportunidades para o sexo feminino e masculino no ambiente organizacional. Entretanto, ainda existe uma clara evidência com relação à desigualdade da participação da mulher no mercado de trabalho, seja quanto aos níveis salariais, possibilidade de crescimento na carreira ou oportunidades de exercer determinadas funções.

Este estudo, ao lançar luz à atuação feminina nos cargos de gestão, objetiva dar maior visibilidade à questão de gênero associada à liderança nas organizações de trabalho. Especificamente, busca contribuir para o rompimento de paradigmas que cerceiam o papel da mulher no contexto econômico-produtivo, de modo que as diferenças deixem de ser naturalizadas e transformam-se em potencializadas. A busca desse entendimento se configura como uma questão muito mais prática do que humanitária ou feminista, uma vez que a bibliografia acerca da liderança converge para o raciocínio básico de que a competitividade entre as organizações e as economias mundiais estão a exigir mudanças em relação à força de trabalho. Deduz-se, então, que usar de todo o talento disponível é uma necessidade competitiva capaz de conduzir à sobrevivência, sucesso ou perpetuidade das organizações de trabalho. E refletir sobre a realidade das práticas femininas quanto à liderança, representa uma forma de contribuição ao processo de mudança pela qual passam.

Para discutir o conceito de gênero, utilizaremos o texto de Lauretis (1994), que discorre sobre as concepções de masculino e feminino, nas quais todos os seres humanos são classificados, formando, em cada cultura, um sistema de gênero, um sistema simbólico ou um sistema de significações que relaciona o sexo a conteudos culturais, de acordo com valores e hierarquias sociais. $O$ uso do termo gênero expressa todo um sistema de relações que inclui sexo, mas que transcende a diferença biológica. $\mathrm{O}$ termo sexo designa somente a caracterização genética e anatomo-fisiológica dos seres humanos. Nesta abordagem, as relações de gênero estão em constante movimento, tendo seu sentido identificado no contexto em que é produzido. Para Louro (2000), gênero é uma construção social feita sobre as diferenças sociais; assim, refere-se ao modo como as diferenças sexuais são compreendidas numa dada sociedade, num determinado grupo, em determinado contexto, ou então, ao modo como elas são trazidas para a prática social e tornadas partes do processo histórico.

Ainda na contextualização de gênero, surge um novo termo que é a divisão sexual do trabalho. Segundo Helena Hirata, esse conceito tem sua origem na França, no início dos anos 1970, sob o impulso do movimento feminista e que tem como abordagem, estudar a distribuição diferencial de homens e mulheres no mercado de trabalho, nas profissões e as variações no tempo e no espaço e analisar como ela se associa à divisão desigual do trabalho doméstico entre os sexos.

Belle (1987, 1993) relata que não existem mais espaços reservados, papéis atribuídos em caráter definitivo, separações estritas ou muros intransponíveis entre o feminino e o masculino. O que se nota é uma segregação velada e disfarçada que atinge as mulheres 
Liderança Feminina Frente ao Mercado de Trabalho no Município de Vassouras no Período de 1970 a 2010

Claudenir Pereira do Val

Primeiros Escritos

(Publicação de Textos, Ensaios e Artigos de Discentes)

em relação ao trabalho, denominado como fenômeno do teto de vidro (Steil 1997), que consiste em uma barreira sutil e transparente, mas suficientemente forte para bloquear a ascensão das mulheres a níveis hierárquicos mais altos.

Para Maria Ednalva Bezerra de Lima, a predominância da exclusão social, o crescimento do desemprego e os ataques permanentes aos direitos sociais têm atingido profundamente e de forma cada vez mais desigual a vida das mulheres no mundo, que têm visto queda de seus salários, o aumento de sua carga de trabalho e sua presença cada vez maior na economia informal. O modo como as mulheres estão inseridas como trabalhadoras, produtoras, reprodutoras da força de trabalho e, principalmente, pela condição de classe, gênero, raça/etnia, orientação sexual, idade, religião e outros aspectos de identidade e nacionalidade têm tornado cada vez mais visível a difícil realidade das trabalhadoras.

Vários estudos e pesquisas já apontaram que as relações entre homens e mulheres são relações que atravessam a sociedade e se articulam com o conjunto das relações sociais; implicam antagonismo ou conflito ligado a relações de dominação e opressão; e podem ser modificadas historicamente.

A inserção da mão de obra feminina no mercado de trabalho desperta a discussão de questões que envolvem a interação entre homens e mulheres nesse ambiente, bem como a trajetória da mulher em cargos de gestão. Apesar do discurso de igualdade de condições e oportunidades, há evidências, como já foi dito, de que existem desigualdades na participação masculina e feminina no mercado de trabalho, seja em relação aos níveis salariais, possibilidade de crescimento na carreira ou oportunidades de exercer determinadas funções. Nesse contexto, a teoria das relações de gênero auxilia a compreensão dessas questões, bem como a discussão do processo de construção da identidade da mulher no mundo dos negócios.

\section{Metodologia}

Com relação aos procedimentos metodológicos, este trabalho utilizará análises bibliográficas acessadas na internet, revistas de liderança e fontes primárias constantes dos arquivos que serão pesquisados.

Inicialmente, procederemos pesquisa sobre a história da Universidade Severino Sombra, no Centro de Documentação Histórica, setor pertencente à USS, no Museu Casa da Hera, e na Prefeitura Municipal de Vassouras.

Para análise da problemática relacionada à liderança feminina nos dias atuais, será realizada pesquisa com mulheres em cargo de liderança no município, com colaboração de alunos do quarto e quinto períodos do curso de Administração da Universidade Severino Sombra, das disciplinas de Administração de Recursos Humanos I e II, as quais leciono. A pesquisa se dará por meio de questionários e entrevistas individuais. Serão pesquisadas empresas de pequeno e médio porte, bancos, escolas, creches, hotéis, 
Liderança Feminina Frente ao Mercado de Trabalho no Município de Vassouras no Período de 1970 a 2010

Claudenir Pereira do Val

Primeiros Escritos

(Publicação de Textos, Ensaios e Artigos de Discentes)

restaurantes, lojas etc. O objetivo da pesquisa é também, identificar quais são as características que as mulheres consideram importantes para o exercício de uma liderança eficaz. Esse trabalho de investigação será de grande importância para os resultados finais e para os alunos envolvidos, visto que, como administradores, exercer papel de liderança eficaz será determinante para o sucesso de suas carreiras profissionais, tendo como referência as gestoras entrevistadas.

Utilizaremos também pesquisa e análise de documentos individuais das funcionárias e ex-funcionárias com cargo de liderança da Universidade Severino Sombra, no período de 1970 a 2010 para a atividade que ora propomos. Essas informações serão pesquisadas em dossiês sob guarda e responsabilidade da Coordenadoria de Recursos Humanos e arquivadas também no Centro de Documentação Histórica. Os dados coletados poderão demonstrar como o número de líderes femininas aumentou no período estudado, e que fatores foram responsáveis por esse aumento.

O uso da documentação escrita (manuscrita e impressa) e das estatísticas elaboradas durante a investigação muito contribuirá para a confecção deste trabalho.

É importante frisar, que a maioria das fontes por nós trabalhadas, até os dias atuais, teve pouca procura para a realização de trabalhos acadêmicos.

Utilizaremos também uma vasta bibliografia de apoio que serviu para balizar as nossas discussões teóricas e metodológicas e que servirá igualmente para contextualizar a elaboração desse estudo dissertativo.

\section{Resultados Esperados}

Tentaremos mostrar, como resultados e conclusões, o levantamento que à luz do período estudado, comprove-se que a mulher tem conseguido conquistar seu espaço na gestão estratégica nas organizações e que esse espaço, a cada dia, tem sido respeitado pelo contingente masculino.

Por meio de pesquisa quantitativa, registro de entrevistas individuais, apresentação de relatórios e gráficos teremos condição de demonstrar como será valiosa a realização desse trabalho para analisar a liderança feminina do município de Vassouras, pois acreditamos que a proposta de se estudar este tema seja inédita, pelo menos no âmbito da Universidade Severino Sombra.

Há de se enfatizar que a implantação da USS nesta cidade de Vassouras foi importante nessa pesquisa, devido à sua contribuição na preparação e qualificação dessas mulheres.

O resultado deste trabalho servirá também para mostrar como a USS tem dado oportunidades várias aos seus funcionários, de modo geral, e não só as mulheres, fazerem carreira. 
Liderança Feminina Frente ao Mercado de Trabalho no Município de Vassouras no Período de 1970 a 2010

Claudenir Pereira do Val

Primeiros Escritos

(Publicação de Textos, Ensaios e Artigos de Discentes)

\section{Notas}

${ }^{1}$ O Segundo Sexo (Le Deuxième Sexe em francês) é um livro escrito por Simone de Beauvoir, publicado em 1949 e uma das obras mais celebradas e importantes para o movimento feminista. O pensamento de Beauvoir analisa a situação da mulher na sociedade. No Brasil, foi publicado em dois volumes. "Fatos e mitos" é o volume 1, e faz uma reflexão sobre mitos e fatos que condicionam a situação da mulher na sociedade. "A experiência vivida" é o volume 2, e analisa a condição feminina nas esferas sexual, psicológica, social e política. Ambos estão esgotados e só podem ser encontrado em sebos. O primeiro volume é divido em três partes: destino, história e mitos.Na primeira parte a autora faz um quadro geral sobre a posição da mulher no mundo, do ponto de vista biológico, psicanalítico e do materialismo histórico.

\section{Fontes de Pesquisa}

Coordenadoria de Recursos Humanos/USS - dossiês de funcionárias.

Centro de Documentação Histórica/USS - dossiês de ex-funcionárias.

Museu Severino Sombra/USS - acervo que permite compreender a trajetória da USS, correspondências oficiais, acervo iconográfico.

Museu Casa da Hera - cartas, livros históricos, jornais etc.

Prefeitura Municipal de Vassouras - dados estatísticos da população e acervo sobre a história do município etc.

\section{Referências Bibliográficas}

REVISTA ESTUDOS FEMINISTAS - O Feminismo no Brasil: suas múltiplas facetas, disponível em http://www.scielo.br/scielo.php?script=sci_arttext\&pid=S0104026X2004000200015

Bennis, Warren; speitzer, Gretchen M.; cummings, Thomas G. O futuro da liderança. $2^{\mathrm{a}}$ ed. São Paulo: Futura, 2001.

Bergamini, Cecília Whitaker. Liderança-administração do sentido. $4^{\mathrm{a}}$ ed. São Paulo: Atlas, 1994.

Brymam, Alan. Liderança nas organizações. In: Clegg, S.R. et. al. Handbook de estudos organizacionais. V. 3. São Paulo: Atlas, 2004.

Cervo, Amado L; BERVIAN, Pedro A. Metodologia científica. $5^{\text {a }}$ ed. São Paulo: Person Education, 2002.

Chiavenato, Idalberto. Introdução à teoria geral da administração. $7^{\mathrm{a}}$ ed. Rio de Janeiro: Elsevier, 2004.

Dedecca, Cláudio Salvadori. Tempo, trabalho e gênero. São Paulo: editora CUT Brasil, 2004. 
Liderança Feminina Frente ao Mercado de Trabalho no Município de Vassouras no Período de 1970 a 2010

Claudenir Pereira do Val

Primeiros Escritos

(Publicação de Textos, Ensaios e Artigos de Discentes)

Drucker, Peter F. O líder do futuro. 10ª ed. São Paulo: Futura 1996.

Gil, Antonio C. Pesquisa social. $5^{a}$ ed.. São Paulo: Atlas S.A.1999.

Hirata, H. ; Kergoat, D. A Classe operária tem dois sexos. Revista Estudos Feministas. Rio de Janeiro, v.2, n.3, 1994.

Kets de Vries, Manfred F. R. Liderança na empresa - como comportamento dos líderes afeta a cultura interna. São Paulo: Atlas, 1997.

Madruga, Lucia R. R.; Gomes, Claudia M.; Fleig, Daniel G. A valorização da mulher no contexto do trabalho: contradições e evidencias identificada na realidade atual. 2001.

Soto, Eduardo. Comportamento organizacional - o impacto das emoções. $2^{\mathrm{a}}$ ed. São Paulo: Atlas 2002.

Wagner III, John A.; Hollenbeck, John R. Comportamento organizacional - criando vantagem competitiva. $4^{a}$ ed. São Paulo: Saraiva, 2002. 